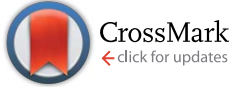

Cite this: RSC Adv., 2017, 7, 6743

\title{
Exfoliating nanomaterials in canola protein derived adhesive improves strength and water resistance $\uparrow$
}

\begin{abstract}
Nandika Bandara, Yussef Esparza and Jianping Wu*
Wood adhesives are mainly produced using petrochemical-based resins. However, concerns over environmental and health effects have prompted a renewed interest on developing bio-based adhesives. The potential of using canola protein for adhesives was explored with limited success. Similar to other proteins, canola adhesives also have weak adhesion and water resistance. The objective of this research was to develop and characterize nanomaterial reinforced canola protein adhesive with improved water resistance and adhesion strength. Hydrophilic bentonite (bentonite), surface modified nanoclay (SMMMT), graphite oxide (GO), and nanocrystalline cellulose (NCC) were exfoliated at different addition levels $(0,1,3,5,10 \% \mathrm{w} / \mathrm{w})$ using an improved solution intercalation method. A significant increase $(p<$ $0.05)$ in both dry and wet adhesion was found at addition levels of $1-3 \%(w / w)$. NCC and GO showed superior effect over bentonite and SM-MMT. The improvement in adhesive strength at low nanomaterial addition was a result of adequate exfoliation of nanomaterials in protein matrix, and increased exposure of functional groups for enhanced interaction with wood surface. This study demonstrated for the first time the potential of nanomaterials for improving adhesion and water resistance of protein-derived adhesive. Canola protein adhesive developed in this study showed its potential for replacing synthetic adhesives as green alternative adhesive materials.
\end{abstract}

Received 28th November 2016
Accepted 21st December 2016

DOI: $10.1039 / c 6 r a 27470 f$

www.rsc.org/advances
Without exception, canola protein derived adhesives also showed poor water resistance and low adhesion strength. ${ }^{7}$

Canola is the second largest oil seed crop in the world and oil processing generates a great deal of meal, containing 35-40\% $\mathrm{w} / \mathrm{w}$ proteins. Irrespective to its high protein content, canola meal has limited uses mainly as a low value animal feed or as a fertilizer., ${ }^{72}$ Canola meal mainly consists of cruciferin (12S), napin (2S) and oleosin with approximate proportions of $\sim 60 \%$, $\sim 20 \%$ and $\sim 8 \%$ respectively. ${ }^{13}$ Cruciferin is a neutral protein (PI - 7.2) with molecular weight of $\sim 300-310 \mathrm{kDa}$ while napin is strongly basic $(\mathrm{PI} \sim 11.0)$ protein because of high proportion of amidated amino acids present in its structure with a molecular weight of $\sim 12.5-14.5 \mathrm{kDa} .{ }^{14}$ Canola protein adhesive prepared by modifying with sodium bisulfite showed dry, wet and soaked adhesion strength values of $5.28 \pm 0.47 \mathrm{MPa}, 4.07 \pm 0.16 \mathrm{MPa}$ and $5.43 \pm 0.28 \mathrm{MPa}$, respectively. ${ }^{15}$ Canola adhesive prepared with $0.5 \%$ sodium dodecyl sulphate (SDS) showed dry, wet, and soaked adhesion strength of $6.00 \pm 0.69,3.52 \pm 0.48 \mathrm{MPa}$, and $6.66 \pm 0.07 \mathrm{MPa}$, respectively. ${ }^{16}$ By grafting poly(glycidyl methacrylate) into canola protein, our study showed improved dry, wet and soaked strength of $8.25 \pm 0.12 \mathrm{MPa}, 3.80 \pm$ $0.15 \mathrm{MPa}$ and $7.10 \pm 0.10 \mathrm{MPa}$ for respectively. ${ }^{7}$ However, the use of high amount of expensive poly(glycidyl methacrylate) polymer $(2.7 \mathrm{~g} / 2 \mathrm{~g}$ protein, w/w) prevents its future commercial exploration. Therefore, there is a need to look for new methods to improve water resistance and adhesion strength of canola protein.
Department of Agricultural, Food and Nutritional Science, University of Alberta, Edmonton, Canada. E-mail: jwu3@ualberta.ca; Fax: +1780492 4265; Tel: +1 780 4926885

$\dagger$ Electronic supplementary information (ESI) available. See DOI: $10.1039 / \mathrm{c} 6 \mathrm{ra} 27470 \mathrm{f}$ 
Nanomaterials are widely used in material science in order to change mechanical, electrical and chemical properties of the bulk material. ${ }^{6}$ For example, in composites research, adding nanomaterials were reported to improve flexural strength, elasticity, toughness and stability of the material. ${ }^{17}$ The potential of nanomaterials in improving adhesive performance was recently explored but with limited success. Kaboorani et al. (2011, 2012) observed slight improvement in adhesion and water resistance after adding montmorillonite, ${ }^{18}$ nano aluminum oxide, ${ }^{19}$ and nanocrystalline cellulose ${ }^{6}$ into polyvinyl acetate adhesives at low nanomaterial concentrations. Research on nanomaterial addition into protein based adhesives was extremely limited. Zhang et al. (2014) reported a decreased adhesion strength of polyisocyanate modified soy protein with the addition of montmorillonite, probably due to a nano scale blocking mechanism. ${ }^{20} \mathrm{Li}$ et al. (2016) recently studied the effect of modified sepiolite-based united crosslinked network in improving adhesion of soybean meal-based wood adhesive and reported an improvement of wet strength from $0.81 \mathrm{MPa}$ to $1.18 \mathrm{MPa} .^{3}$ Another recent study by Qi et al. (2016) reported an improvement of wet adhesion from $2.9 \mathrm{MPa}$ to $4.3 \mathrm{MPa}$ by exfoliating sodium montmorillonite at $8 \% \mathrm{w} / \mathrm{w}$ addition rate into soy protein isolate. ${ }^{21}$ Both studies suggest that "physical filling effect" of sepiolite, ${ }^{3}$ and nanomaterial induced crosslinking of protein network as the key factors contributing towards improving adhesion. ${ }^{3,21}$ It is well recognized that proper dispersion and exfoliation of nanomaterials is a critical factor in their applications. ${ }^{22}$ Therefore, it is necessary to develop new methods for exfoliating nanomaterials in protein-based adhesives matrix.

We hypothesized that a proper dispersion of nanomaterials into canola protein adhesive would improve water resistance and adhesion strength. The main objective of this study is to develop and characterize nanomaterial reinforced canola protein adhesive with improved water resistance and adhesion strength. Effects of addition levels and intercalation conditions of nanomaterials such as hydrophilic bentonite (Bento), surface modified montmorillonite (with $25-30 \%$, w/w trimethyl octadecylammonium chloride-SM-MMT), nanocrystalline cellulose (NCC), and graphite oxide (GO) were studied in this research. These nanomaterials have been selected based on the strong evidence found in literature in improving functional properties of adhesives, composites and plastic research..$^{6,18,23,24}$ Nanoclays are hydrated material made with either tetrahedral or octahedral stacks of silicate sheets. ${ }^{25}$ Bentonite is typically considered as an impure form of clays that contain both montmorillonite and other crystalline structures, arranged in a octahedral sheet sandwich between two tetrahedral plates and an isolated additional octahedral plate. ${ }^{26}$ Montmorillonite is a naturally hydrophilic and inorganic material that made with two stacked layers of tetrahedral sheets around a middle octahedral sheet, and usually contains hydrated $\mathrm{Na}^{+}$or $\mathrm{K}^{+}$ions. ${ }^{25,26}$ Montmorillonite used for this study is modified with $25-30$ (\%, w/w) trimethyloctadecylammonium chloride to improve interlayer spacing and hydrophobicity. GO consists of oxidized graphite sheets (or graphene oxide sheets) as their basal planes while surface of the sheet is decorated mostly with epoxide, hydroxyl, carbonyl and carboxyl groups. ${ }^{27}$ Nanocrystalline cellulose (NCC) is derived from acid hydrolysis of native cellulose and shows a rigid rodlike crystals with diameter in the range of 10-20 $\mathrm{nm}$ and lengths of a few hundred nanometers. ${ }^{28}$

\section{Experimental section}

\section{Materials and chemicals}

Canola meal was a generous gift from Richardson Oilseed Ltd. (Lethbridge, AB, Canada). Hydrophilic bentonite (Bento), surface modified montmorillonite (SM-MMT), graphite and cellulose were purchased from Sigma-Aldrich (Sigma Chemical Co, St. Louise, MO, USA). All chemicals were from Fisher Scientific (Ottawa, ON, Canada) unless otherwise noted.

\section{Method}

Canola protein extraction. Proteins were extracted from canola meal as described by Manamperi et al., $(2010)^{12}$ with slight modifications. Canola meal was ground to pass through 100-mesh size using a Hosokawa milling and classifying system (Hosokawa Micron Powder Systems, Summit, NJ, USA). Canola meal was mixed with mili-Q water in $1: 10(\mathrm{w} / \mathrm{v})$ ratio; $\mathrm{pH}$ was adjusted to 12.0 using $3 \mathrm{M} \mathrm{NaOH}$ and stirred for $30 \mathrm{~min}$ followed by centrifugation $\left(10000 g, 15 \mathrm{~min}, 4{ }^{\circ} \mathrm{C}\right)$. The supernatant was collected, readjust $\mathrm{pH}$ to 4.0 using $3 \mathrm{M} \mathrm{HCl}$ and centrifuged as above after $30 \mathrm{~min}$ stirring. The resulting precipitate was collected, freeze-dried and stored at $-20{ }^{\circ} \mathrm{C}$ until further use.

Graphite oxide preparation. Graphite oxide nanoparticles (GO) were prepared according to Hummers and Offeman method ${ }^{29}$ with slight modifications. In brief, $5 \mathrm{~g}$ of graphite and $2.5 \mathrm{~g}$ of $\mathrm{NaNO}_{3}$ was mixed in a glass beaker where $120 \mathrm{~mL}$ of concentrated $\mathrm{H}_{2} \mathrm{SO}_{4}$ was slowly added while stirring for $30 \mathrm{~min}$ (200 RPM) in an ice bath to oxidize graphite. Then, $15 \mathrm{~g}$ of $\mathrm{KMnO}_{4}$ was slowly added to the mixture while maintaining temperature at $35 \pm 3{ }^{\circ} \mathrm{C}$ and stirred for $1 \mathrm{~h}$. After the reaction, $92 \mathrm{~mL}$ of deionized water was added to the reaction mixture, and stirred for $15 \mathrm{~min}$. Leftover $\mathrm{KMnO}_{4}$ was neutralized by adding another $80 \mathrm{~mL}$ of hot $\left(60^{\circ} \mathrm{C}\right)$ deionized water containing $3 \% \mathrm{H}_{2} \mathrm{O}_{2}$. After cooling to room temperature, the sample was centrifuged $\left(10000 \mathrm{~g}, 15 \mathrm{~min}, 4{ }^{\circ} \mathrm{C}\right)$ to remove any remaining acid and chemicals. The precipitate was washed for three times as above to prepare oxidized graphite, followed by $5 \mathrm{~min}$ sonication (at $50 \%$ power output), before freeze drying.

Nanocrystalline cellulose preparation. Nanocrystalline cellulose (NCC) was prepared from cellulose samples as described by Cranston and Gray $(2006)^{30}$ with slight modifications. Cellulose hydrolysis was carried out by mixing $20 \mathrm{~g}$ of cellulose powder with $350 \mathrm{~mL}$ of $64 \%$ (w/w) sulfuric acid under continuous stirring for $45 \mathrm{~min}$ at $45^{\circ} \mathrm{C}$. The mixture was diluted 10 times with deionized water in order to suspend the reaction and centrifuged $\left(10000 \mathrm{~g}, 4{ }^{\circ} \mathrm{C}, 10 \mathrm{~min}\right)$ to remove excessive acid. The resulting precipitate was washed with deionized water, and centrifuged to remove any remaining chemicals. Extracted NCC was dialyzed for three days against deionized 
water until neutral $\mathrm{pH}$ achieved, freeze-dried, and stored at $-20{ }^{\circ} \mathrm{C}$ until further use.

Exfoliation of nanomaterials and adhesive preparation. A solution intercalation method was developed to exfoliate nanomaterials into canola protein matrix. In brief, $3 \mathrm{~g}$ of canola protein was mixed with $20 \mathrm{~mL}$ of deionized water to make $15 \%$ $\mathrm{w} / \mathrm{v}$ dispersion. Samples were stirred for $6 \mathrm{~h}(300 \mathrm{rpm}, \mathrm{RT})$ to disperse canola protein, and $\mathrm{pH}$ was readjusted to 5.0 using $1 \mathrm{M}$ $\mathrm{HCl}$ solution. Nanomaterials at various concentrations (to have final concentrations of $0 \%, 1 \%, 3 \%, 5 \%$, and $10 \% \mathrm{w} / \mathrm{w}$, nanomaterial/protein) were separately dispersed in $10 \mathrm{~mL}$ deionized water, stirred for $5 \mathrm{~h}$ at room temperature (300 rpm) and another $1 \mathrm{~h}$ at $45 \pm 3{ }^{\circ} \mathrm{C}$. Dispersed nanomaterials were sonicated for 3 min using a medium size tapered tip attached to a high intensity ultrasonic dismembrator (Model 500, Thermo Fisher Scientific INC, Pittsburg, PA, USA) providing intermittent pulse dispersion of $5 \mathrm{~s}$ at $3 \mathrm{~s}$ intervals and $60 \%$ amplitude. Resulting nanomaterial dispersions were homogenized for $2 \mathrm{~min}$ at $20000 \mathrm{rpm}$ using digital ULTRA TURRAX high shear homogenizer (Model T25 D S1, IKA ${ }^{\circledR}$ Works, Wilmington, NC, USA). Then, prepared nanomaterial dispersions were slowly added to protein dispersions dropwise while stirring for $15 \mathrm{~min}$ to have a final protein concentration of $10 \% \mathrm{w} / \mathrm{v}$. Following the intercalation, protein-nanomaterial mixture was sonicated and homogenized as above and the $\mathrm{pH}$ of the adhesive mixture was readjust to 12.0 by adding $6 \mathrm{M} \mathrm{NaOH}$ solution. Negative controls were prepared by dispersing canola protein in deionized water at $10 \% \mathrm{w} / \mathrm{v}$ ratio and used as is. In the $\mathrm{pH}$ controls, canola protein samples were dispersed in deionized water at $10 \% \mathrm{w} / \mathrm{v}$ ratio, but adjust the $\mathrm{pH}$ to 12.0 similar to nanomaterial reinforced samples, without adding nanomaterials. Solution intercalation method developed by Zhang et al. (2014) was used to produce canola protein adhesives from SM-MMT and NCC for the purpose of comparing water resistance and adhesion of the method developed in our lab. ${ }^{20}$

Adhesion strength measurement. Birch veneer samples with a thickness of $1.2 \mathrm{~mm}$ were cut into a dimension of $20 \mathrm{~mm} \times$ $120 \mathrm{~mm}$ (width and length) using a cutting device (Adhesive Evaluation Systems, Corvallis, OR, USA). They were conditioned according to the requirement of ASTM (American Society for Testing and Materials) standard method D2339-98 (2011) ${ }^{31}$ at $23{ }^{\circ} \mathrm{C}$ and $50 \%$ relative humidity in a controlled environment chamber (ETS 5518, Glenside, PA, USA). The prepared adhesive samples were spread at an amount of $40 \mu \mathrm{L}$ per veneer strand in a contact area of $20 \mathrm{~mm} \times 5 \mathrm{~mm}$ using a micropipette. After adhesive application, veneer samples were air dried for $5 \mathrm{~min}$, followed by hot pressing at $120^{\circ} \mathrm{C}$ and $3.5 \mathrm{MPa}$ for $10 \mathrm{~min}$ using Carver manual hot press (Model 3851-0, Carver Inc, In, USA). Dry adhesion strength (DAS) was measured according to ASTM standard method D2339-98 (2011) by measuring tensile loading required to pull bonded veneer using Instron machine (Model 5565 , Instron, MA, USA) equipped with a $5 \mathrm{kN}$ load cell and data was collected using Bluhill 3.0 software (Instron, MA, USA). Wet adhesion strength (WAS) and soaked adhesion strength (SAS) were measured according to ASTM standard D1151-00 (2013) ${ }^{32}$ using Instron tensile loading. WAS values were measured after submerging bonded veneer samples for $48 \mathrm{~h}$ in water $\left(23^{\circ} \mathrm{C}\right)$ while SAS was measured after reconditioning submerged wet samples for another seven days at $23{ }^{\circ} \mathrm{C}$ and $50 \%$ relative humidity in a controlled environment chamber. In each strength testing (DAS, WAS and SAS) minimum four bonded veneer samples per replicate was used. All samples were clamped to instron with a $35 \mathrm{~mm}$ gauge length and tested at $10 \mathrm{~mm}$ $\min ^{-1}$ cross head speed.

Differential scanning calorimetry (DSC). Thermal properties in prepared nanomaterials and adhesive samples were analyzed using differential scanning calorimeter (Perkin-Elmer, Norwalk, CT, USA). Temperature and heat flow were calibrated using pure indium samples. Moisture in the samples was removed by freeze-drying followed by drying in a hermetic desiccator containing $\mathrm{P}_{2} \mathrm{O}_{5}$ for two weeks before analysis. Nanomaterial and adhesive samples were accurately weighed into T-Zero hermetic aluminum pans ( $\sim 6 \mathrm{mg}$ each), mixed with $60 \mu \mathrm{L}$ of $0.01 \mathrm{M}$ phosphate buffer, hermetically sealed with lids, and analyzed against an empty reference pan under continuous nitrogen purging. All samples were equilibrated at $0{ }^{\circ} \mathrm{C}$ for $10 \mathrm{~min}$ and heated from 0 to $250{ }^{\circ} \mathrm{C}$ at a ramping rate of $10{ }^{\circ} \mathrm{C} \mathrm{min}^{-1}$. Thermodynamic data was collected and analyzed using Universal Analysis 2000 software for thermal transition changes in adhesives and nanomaterials (Perkin-Elmer, Norwalk, CT, USA).

Fourier transform infrared spectroscopy (FTIR). FTIR was used to characterize nanomaterial induced secondary structural changes of canola proteins using Nicolet 8700 Fourier transform infrared spectrometer (Thermo Eletron Co. WI, USA). Moisture in the samples was removed by freeze drying followed by drying in a hermetic desiccator containing $\mathrm{P}_{2} \mathrm{O}_{5}$ for two weeks before analysis. Graphite, GO, NCC, and nanomaterial reinforced adhesive samples were mixed with potassium bromide ( $\mathrm{KBr})$, and milled to make a fine powder before FTIR analysis. IR spectra in the range of $400-4000 \mathrm{~cm}^{-1}$ were collected using 128 scans at a resolution of $4 \mathrm{~cm}^{-1}$. Collected data were processed and analyzed with Origin 2016 software (OriginLab Corporation, MA, USA), where the second derivative of FTIR spectra was used to identify the protein secondary structural changes.

X-ray diffraction. X-ray diffraction (XRD) of nanomaterial reinforced adhesive samples was performed using Rigaku Ultima IV powder diffractometer (Rigaku Co. Japan). Cu-K $\alpha$ radiation $(0.154 \mathrm{~nm})$ was used to collect the angle data $(2 \theta)$ from 5 to 50 degrees. XRD data was processed using Origin 2016 software (OriginLab Corporation, MA, USA) for nanomaterialreinforced adhesives to identify the dispersion pattern at different nanomaterial concentrations. Interlayer distance of nanomaterials were calculated using the Bragg's equation; ${ }^{33}$ $\sin \theta=n \lambda / 2 d$, where $\lambda$ is the wavelength of X-ray radiation used in the experiment, $d$ is the spacing between diffraction lattice (interlayer spacing), and $\theta$ is the glancing angle (measured diffraction angle). ${ }^{18,34}$

Transmission electron microscopy (TEM). Transmission electron microscopy analysis was performed using Philips/FEI transmission electron microscope (Model Morgagni, FEI Co, OR, USA) coupled with Getan digital camera (Getan Inc, CA, USA). For nanomaterials, samples were dispersed in ethanol at 
a concentration of $0.5 \% \mathrm{w} / \mathrm{w}$ whereas adhesive samples were diluted to 100 fold with ethanol before TEM imaging. A drop of prepared solution was casted onto 200 mesh holey copper grid covered with carbon film and allowed for air drying before imaging. For NCC sample and adhesive containing NCC, 1\% w/ $\mathrm{w}$ uranyl acetate drop was added onto air dried drop in the copper grid in order to improve the contrast of NCC fibres.

Statistical analysis. Data were analyzed using analysis of variance (ANOVA) followed by Duncan's Multiple Range (DMR) test to identify the effects of each nanomaterial concentration on adhesion strength (dry, wet, soaked) using Statistical Analysis System Software (SAS version 9.4, SAS Institute, Cary, NC). Effect of nanomaterial concentrations on adhesion strength of each nanomaterial was evaluated at the $95 \%$ confidence level.

\section{Results and discussion}

\section{Characterization of nanomaterials}

Fig. 1 shows the diffraction angles and interlayer spacing of nanomaterials used in this study. Both bentonite and SM-MMT show similar crystalline peaks around diffraction angles of $19.7^{\circ}, 34.9^{\circ}$, and $54.0^{\circ}$ with interlayer spacing of $0.450 \mathrm{~nm}$, $0.257 \mathrm{~nm}$, and $0.167 \mathrm{~nm}$, respectively. Kaboorani and Riedl (2011) also observed similar intense peaks in unmodified montmorillonite clay. ${ }^{18}$ The crystalline peaks at $6.6^{\circ}$ and $28.7^{\circ}$ in bentonite has shifted to $5.6^{\circ}$ and $26.5^{\circ}$ in SM-MMT whereas their corresponding interlayer spacing have shifted from 1.346 and $0.310 \mathrm{~nm}$ to 1.559 and $0.336 \mathrm{~nm}$, respectively. Surface modification of montmorillonite with $25-30 \%(\mathrm{w} / \mathrm{w})$ trimethyloctadecylammonium chloride polymer is known to cause changes of diffraction angle and the increase in interlayer spacing. ${ }^{35,36}$

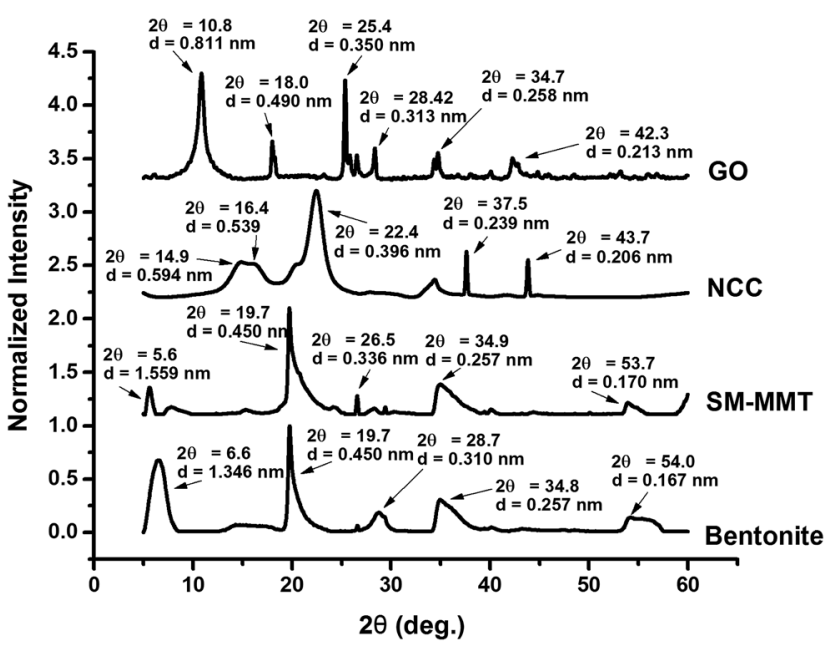

Fig. 1 X-ray diffraction patterns show glancing angle $(\theta)$ and interlayer spacing $(d)$ of bentonite, SM-MMT (surface modified montmorillonite), NCC (nanocrystalline cellulose) and GO (graphite oxide) used in the adhesive preparation. Notes: X-ray diffraction data of the nanomaterials were collected at the glancing angle $(2 \theta)$ range of $5-60^{\circ}$ and interlayer spacing $(d)$ was calculated according to the Bragg's equation: $\sin \theta=n \lambda / 2 d$.
Crystallinity and interlayer spacing of NCC depend on the method of preparation. ${ }^{37,38}$ NCC samples show three characteristic cellulose crystalline peaks at $14.9^{\circ}, 16.4$ and $22.4^{\circ}$ with interlayer spacing of $0.594 \mathrm{~nm}, 0.539 \mathrm{~nm}$ and $0.396 \mathrm{~nm}$, respectively. Cellulose crystalline peaks at similar diffraction angels were previously reported. ${ }^{37,38}$ In addition, two other minor peaks were shown at $37.5^{\circ}$, and $43.7^{\circ}$ diffraction angles with interlayer spacing of $0.239 \mathrm{~nm}$ and $0.213 \mathrm{~nm}$, respectively. GO samples show two major peaks at $10.8^{\circ}$ and $25.4^{\circ}$ with interlayer spacing of $0.811 \mathrm{~nm}$ and $0.350 \mathrm{~nm}$. In addition, three minor peaks were observed in the prepared GO at $18.0^{\circ}, 34.7^{\circ}$ and $42.3^{\circ}$ angles with $d$ space of $0.490 \mathrm{~nm}, 0.258 \mathrm{~nm}$ and $0.213 \mathrm{~nm}$, respectively. The interlayer spacing of GO mainly depends on their oxidation level and $\mathrm{C}: \mathrm{O}$ ratio; ${ }^{39} \mathrm{GO}$ prepared for this study has a C : O ratio of 2.18 (Fig S1: ESI $\dagger$ ). Krishnamoorthy et al. (2013) identified similar crystalline peaks for graphite oxide prepared under different oxidation conditions. They attributed the peak at $10.8^{\circ}$ to an oxidation product whereas the peak at $\sim 25.4^{\circ}$ to crystallinity of graphite. In the same study they observed changes in diffraction angle and interlayer spacing with different oxidation conditions. ${ }^{39}$ TEM images of nanomaterials are shown in Fig. 2. Both bentonite and SM-MMT showed the platelet like structure at $\sim 80-150 \mathrm{~nm}$ whereas NCC samples appear to be in a long rod like fibers at $\sim 60-90 \mathrm{~nm}$ diameters. GO appeared to be thin sheets stacked one another with average width of $\sim 600-800 \mathrm{~nm}$.

\section{Dispersion of nanomaterials in canola protein}

Previous studies on dispersing NCC, nanoclay, and $\mathrm{Al}_{2} \mathrm{O}_{3}$ nano particle in PVA adhesives suggested that homogeneous dispersion/exfoliation of nanomaterials is the key to improve adhesion strength. ${ }^{\mathbf{6} 18,19}$ Fig. 3 shows the TEM images of nanomaterial dispersion in canola adhesive samples at different concentrations. At a $1 \%$ addition level, all four nanomaterials were exfoliated where they dispersed completely and randomly in the protein matrix. ${ }^{\mathbf{1 8 , 4 0}}$ However, aggregation of clay platelets started to be visible at 3, 5 and $10 \%$ (w/w of protein) addition levels in bentonite and SM-MMT samples. Similar results were observed in previous studies on nanoclay and $\mathrm{Al}_{2} \mathrm{O}_{3}$ dispersed PVA adhesives where aggregation of nanoclay platelets were reported at concentrations greater than $4 \%{ }^{\mathbf{1 8 , 1 9}}$ In terms of NCC and GO, exfoliation was observed up to $5 \%$ (w/w of protein) addition level whereas aggregation was visible at $10 \%(\mathrm{w} / \mathrm{w}$ of protein) addition level. The presence of surface hydrophilic groups such as $-\mathrm{OH}$ and $-\mathrm{COOH}$ in $\mathrm{NCC}$ and GO might be the reason for better exfoliation in canola protein matrix than those of bentonite and SM-MMT.

$\mathrm{X}$-ray diffraction of nanomaterial dispersed canola protein adhesives are shown in Fig. 4. XRD patterns of dispersed nanomaterials supported the results observed in TEM. In a situation where nanomaterials are properly exfoliated in the matrix, crystalline peaks of original nanomaterial should not be visible since exfoliated nanomaterial could not generate identical peaks due to the absence of similar crystal lattice. ${ }^{\mathbf{1 8 4 0}}$ XRD patterns of bentonite and SM-MMT exhibit a similar trend where the exfoliation of nanomaterials was observed only in $1 \%$ 

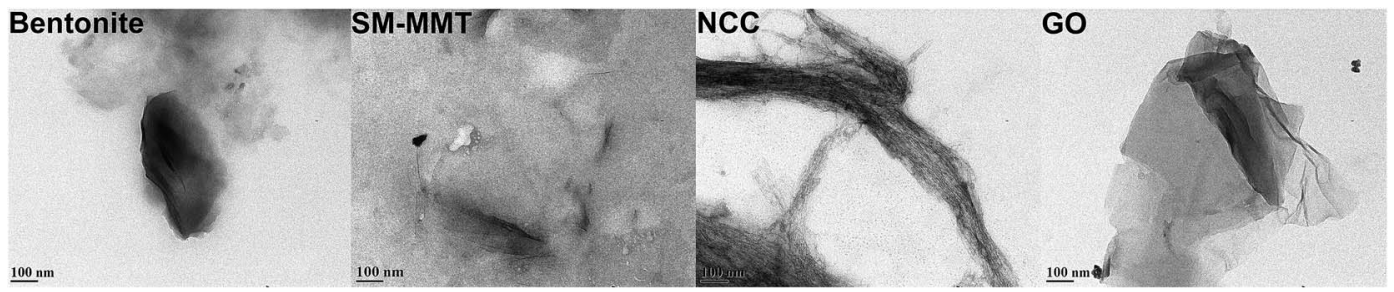

Fig. 2 Transmission electron microscopic images of bentonite, SM-MMT (surface modified montmorillonite), NCC (nanocrystalline cellulose) and GO (graphite oxide) used for adhesive preparation.
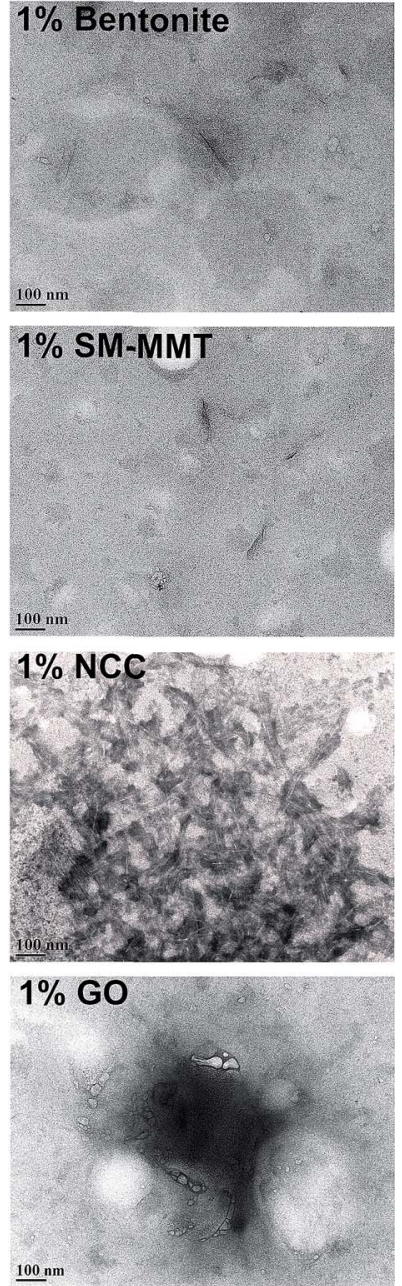
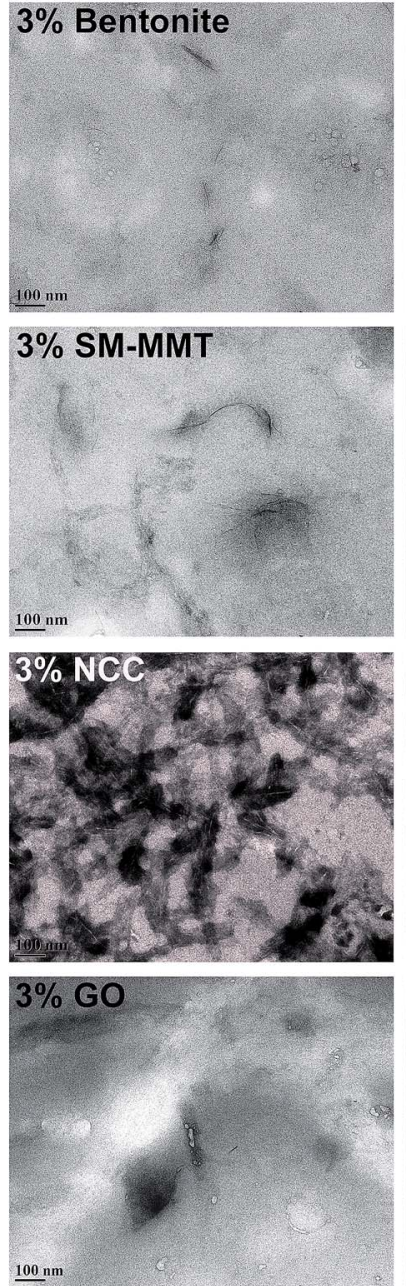
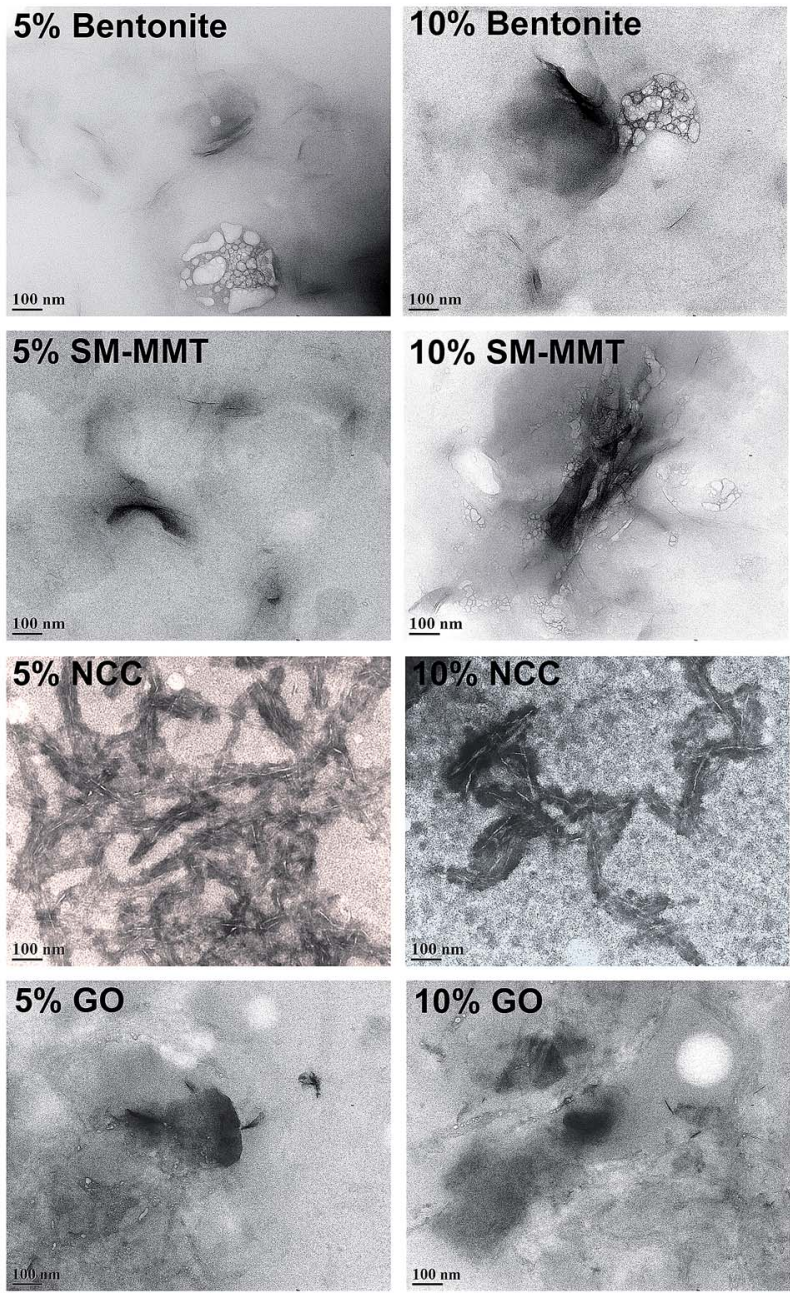

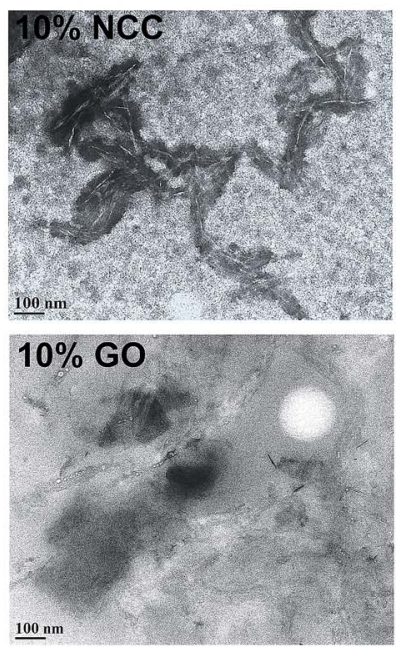

Fig. 3 Transmission electron microscopic images of canola protein adhesives after exfoliating 1\%, 3\%, 5\%, and 10\% (w/w nanomaterial/canola protein) levels of bentonite, SM-MMT (surface modified montmorillonite), NCC (nanocrystalline cellulose) and GO (graphite oxide).

(w/w of protein) addition level. Characteristic nanoclay peaks arising at $5.6^{\circ}, 19.7^{\circ}$, and $34.8^{\circ}$ start to appear in bentonite and SM-MMT incorporated adhesives after increasing the nanomaterial addition up to $3 \%$ or above. This can be due to partial exfoliation of nanomaterials or aggregation of nanoclay platelets at higher concentrations. Kaboorani and Riedl $(2011,2012)$ observed similar trend in XRD patterns where, nanomaterial loading above $4 \%$ exhibit crystalline peaks similar to their original nanomaterials in montmorillonite and nano $\mathrm{Al}_{2} \mathrm{O}_{3}$ dispersed in PVA adhesives. ${ }^{18,19}$
In comparison, NCC and GO show better exfoliation in canola protein as original NCC and GO crystalline peaks were not visible in XRD patterns up to $5 \%$ addition level. However, at $10 \%$ (w/w of protein) addition level, both NCC and GO exhibit respective crystalline peaks in XRD patterns of prepared adhesives. In a previous study with NCC reinforced PVA adhesive, NCC showed exfoliation only up to $3 \%$ addition with improved wet adhesion than PVA adhesives reinforced with nanoclay. ${ }^{6,18}$ The improved solution intercalation method we used to disperse nanomaterials in canola protein might be the reason 
A

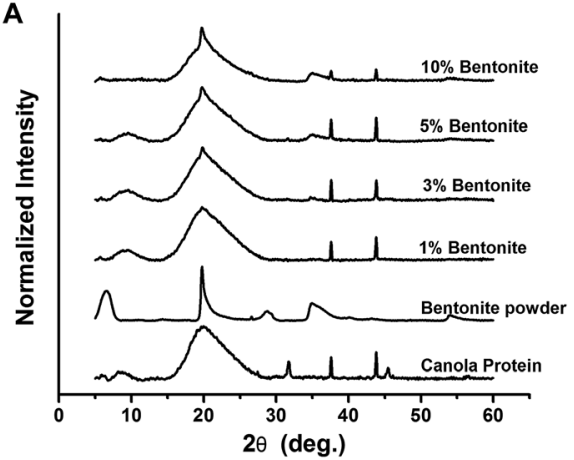

C

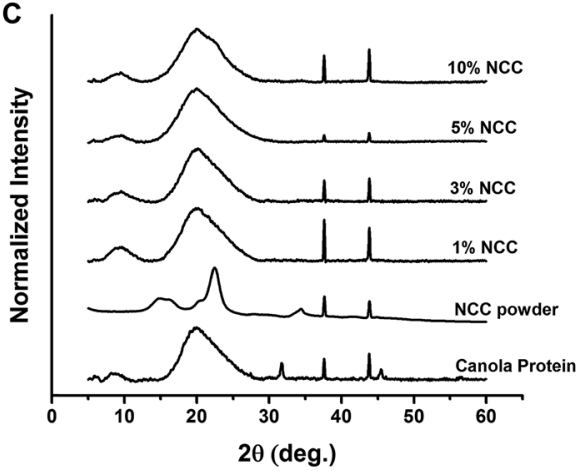

B
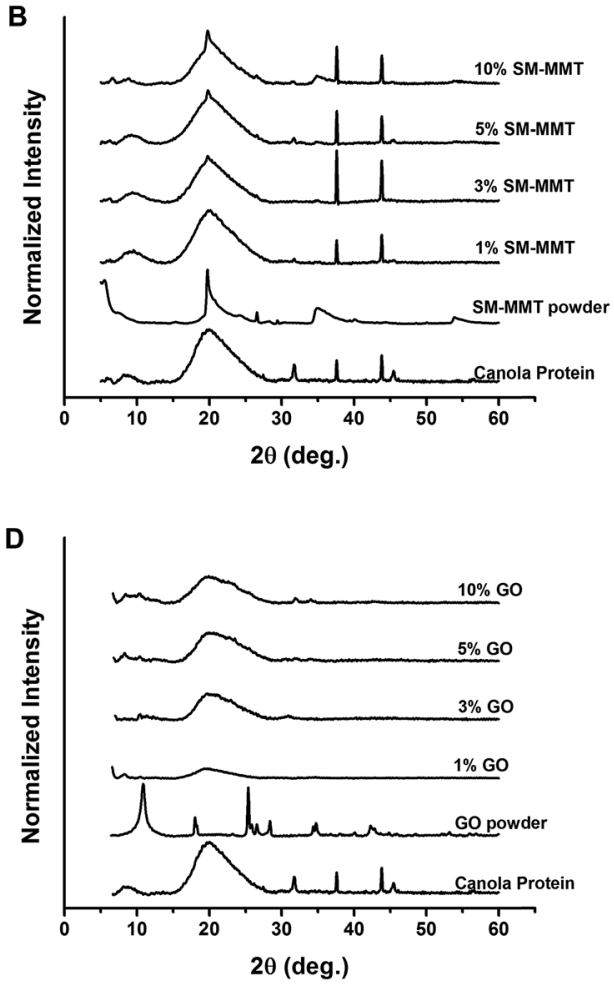

Fig. 4 X-ray diffraction patterns of canola protein adhesives after exfoliating 1\%, 3\%, 5\%, and 10\% (w/w nanomaterial/canola protein) levels of bentonite, SM-MMT (surface modified montmorillonite), NCC (nanocrystalline cellulose) and GO (graphite oxide).

for improved exfoliation observed in NCC and GO up to 5\% addition level.

\section{Effect of nanomaterial type and their concentration on adhesion strength}

Effects of different nanomaterials and concentrations on adhesion strength are shown in Fig. 5. Adding nanomaterials at low concentrations significantly improved adhesion strength compared to both $\mathrm{pH}$ and negative controls. Bentonite significantly increased dry strength from $6.38 \pm 0.84 \mathrm{MPa}$ to $7.65 \pm$ $1.33 \mathrm{MPa}$ at $1 \%(\mathrm{w} / \mathrm{w})$ addition and to $8.50 \pm 1.27 \mathrm{MPa}$ at $3 \%(\mathrm{w} /$ w) addition (Fig. 5A). The wet strength was also increased from $1.98 \pm 0.22 \mathrm{MPa}$ (pH control) to $2.80 \pm 0.50 \mathrm{MPa}$ and $2.44 \pm$ $0.29 \mathrm{MPa}$ at $1 \%$ and $3 \%(\mathrm{w} / \mathrm{w})$ addition respectively. However, the soaked strength was not affected by bentonite addition. A similar trend was observed with the addition of SM-MMT (Fig. 5B). At 1\% SM-MMT addition, the dry, wet and soaked strengths were significantly increased up to $9.29 \pm 1.53 \mathrm{MPa}$, $3.19 \pm 0.57 \mathrm{MPa}$, and $6.87 \pm 1.29 \mathrm{MPa}$ respectively. However, the strength values were reduced at increasing bentonite/SMMMT addition levels, which may be due to partial exfoliation or aggregation of nanomaterials at higher concentration as evidenced by TEM and XRD. Aggregation of nanomaterials at higher concentrations were previously reported in metal oxide nanomaterials and carbon nanotubes in different matrixes, mainly due to interaction with functional groups in polymer. ${ }^{41,42}$ Similarly, aggregation of bentonite and SM-MMT might reduce the functional groups available for interacting with wood surface, thereby decreasing adhesion strength.

In comparison, both NCC and GO exhibited a better exfoliation even under higher addition levels up to $5 \%$ as evidenced by TEM and XRD, which was in good agreement with improved adhesion strength with NCC and GO addition (Fig. 5C and D). NCC significantly increased both dry and wet strength $(10.37 \pm$ $1.63 \mathrm{MPa}$ and $3.57 \pm 0.57 \mathrm{MPa}$ respectively) at $1 \%(\mathrm{w} / \mathrm{w})$ addition level while the highest soaked strength $(8.98 \pm 1.15 \mathrm{MPa})$ was observed at $3 \%(\mathrm{w} / \mathrm{w})$ NCC addition. Unlike bentonite and SM-MMT, all tested NCC and GO addition levels significantly increased the adhesion and water resistance compared to negative and $\mathrm{pH}$ control samples. The highest dry and soaked strength for $\mathrm{GO}(9.27 \pm 1.24 \mathrm{MPa}, 7.78 \pm 0.45 \mathrm{MPa}$ respectively $)$ was observed at $5 \%(\mathrm{w} / \mathrm{w})$ concentration whereas the highest wet strength for GO $(3.25 \pm 0.36 \mathrm{MPa})$ was observed at $1 \%(\mathrm{w} / \mathrm{w})$ concentration. Adhesive prepared by our exfoliation method exhibited significantly higher water resistance and adhesion than that prepared by the method reported by Zhang et al. (2014) (Table S1: ESI †).

Our study further supported the importance of uniform dispersion/exfoliation of nanomaterial in adhesive application, which was in good agreement with previous reports in improving mechanical properties of polymer matrix. ${ }^{6,18,19}$ The adhesive strength of soy protein adhesive was not improved when $\mathrm{SiO}_{2}$ nano particles was not homogenously dispersed and exfoliated..$^{40}$ Adding high level of montmorillonite could even reduce the adhesive strength, due to a nano scale blocking 

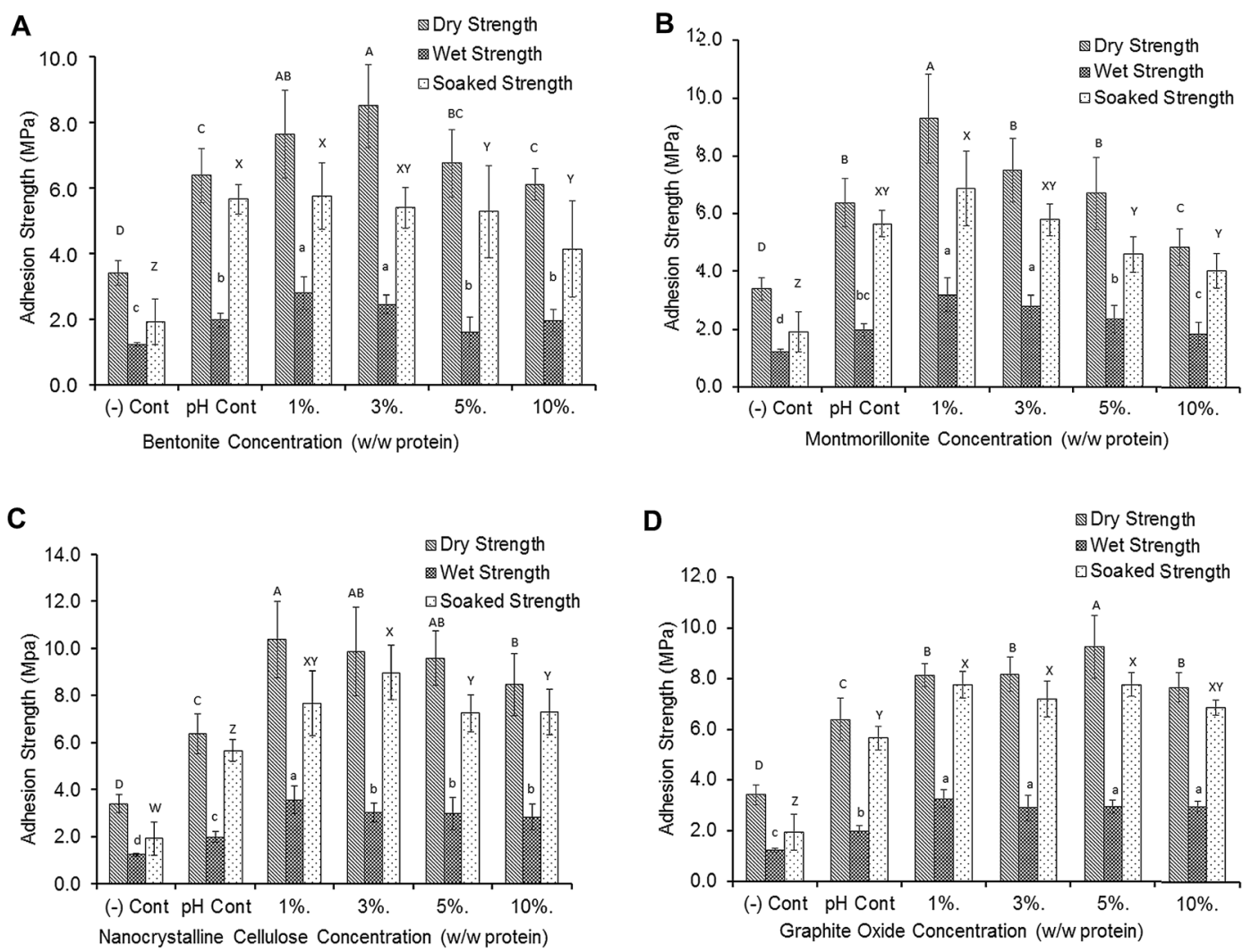

Fig. 5 Adhesion strength of nanomaterial exfoliated canola protein adhesives after exfoliating 1\%, 3\%, 5\%, and 10\% (w/w nanomaterial/canola protein) levels of bentonite, SM-MMT (surface modified montmorillonite), NCC (nanocrystalline cellulose) and GO (graphite oxide). All adhesive samples were prepared in triplicate $(n=3)$ and minimum 5 wood samples per replicate were used for each strength measurement. Adhesion data was analyzed using one-way ANOVA followed by Duncan test for mean separation for dry, wet and soaked adhesion separately. Different letters on the bar represent significantly different adhesion strength $(p<0.05)$

mechanism. ${ }^{20}$ Zhang et al. (2014) suggested that enhanced interactions between MMT and soy protein could make functional groups unavailable for reacting with wood surface, thus reducing adhesion strength. Adhesion between adhesive-wood interface results from various interactions including chemical bonding and mechanical interlocking. ${ }^{43}$ The exfoliated nanomaterials have the potential to affect both chemical bonding and mechanical interlocking thereby increasing adhesion. The presence of nanomaterials in an exfoliated state in the adhesive matrix could act as a physical barrier for water penetration; ${ }^{3}$ it may also improve cohesion by increasing protein-protein interactions as a cross linker ${ }^{3,20,21}$ which ultimately improves wet and dry adhesion strength. In addition, adding nanomaterials would also induce protein structural changes by exposing hydrophobic and other berried functional groups ${ }^{44}$ enabling reaction with functional groups present in surface and inner layers of the wood during adhesive penetration and subsequent curing.

\section{Effect of nanomaterial on structural changes in canola protein based wood adhesives}

Effects of nanomaterial addition on protein secondary structure are shown in Fig. 6. Protein secondary structural changes after modifications can be identified by processing amide I peak, typically generated by $\mathrm{C}=\mathrm{O}$ and $\mathrm{C}-\mathrm{N}$ stretching vibrations at $1600-1700 \mathrm{~cm}^{-1}$ wavelength. ${ }^{45,46}$ The CPI pH control samples are predominated by $\beta$ sheet structure ${ }^{45,46}$ with fitted peaks allocated at $1626 \mathrm{~cm}^{-1}, 1639 \mathrm{~cm}^{-1}$, and $1676 \mathrm{~cm}^{-1}$ in the second derivative spectra, followed by $\alpha$-helix and turns with peaks found at $1657 \mathrm{~cm}^{-1}$ and $1695 \mathrm{~cm}^{-1}$ respectively ${ }^{45}$ (Fig. S2 - ESI†). In all nanomaterial added samples, in particular at concentrations over $3 \%$, there is an increase in unordered structure as the peak at $1641 \mathrm{~cm}^{-1}$ increased. ${ }^{45,46}$

At increasing bentonite addition, the relative proportion of $\beta$ sheet structures $\left(1628 \mathrm{~cm}^{-1}, 1676 \mathrm{~cm}^{-1}\right)$ was decreasing while that of unordered structures $\left(1641 \mathrm{~cm}^{-1}\right)$ was increasing (Fig. 6a). Similar trend was also observed with SM-MMT addition (Fig. S2 and S3 - ESI $\dagger$ ). In addition, at high nanomaterial concentrations, a peak shift from $1695 \mathrm{~cm}^{-1}$ towards $1691 \mathrm{~cm}^{-1}$ also represent turns in secondary structure of modified proteins..$^{45}$ In both type of nanoclay, increasing nanomaterial did reduce the relative proportion of $\alpha$-helical structures as well (Fig. S2 and S3 - ESI†).

NCC addition reduced the relative proportion of $\beta$ sheet structure $\left(1628 \mathrm{~cm}^{-1}\right.$ and $1675 \mathrm{~cm}^{-1}$ wavelengths) while the proportion of $\alpha$-helical structure $\left(1657 \mathrm{~cm}^{-1}\right)$ increased at high NCC concentrations (Fig. 6c). Unlike nanoclay, the unordered structure $\left(1641 \mathrm{~cm}^{-1}\right)$ was not visible in second derivative 
A

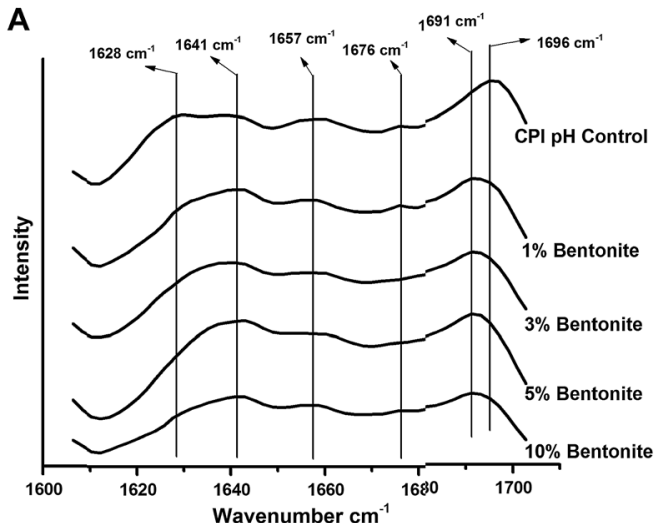

C

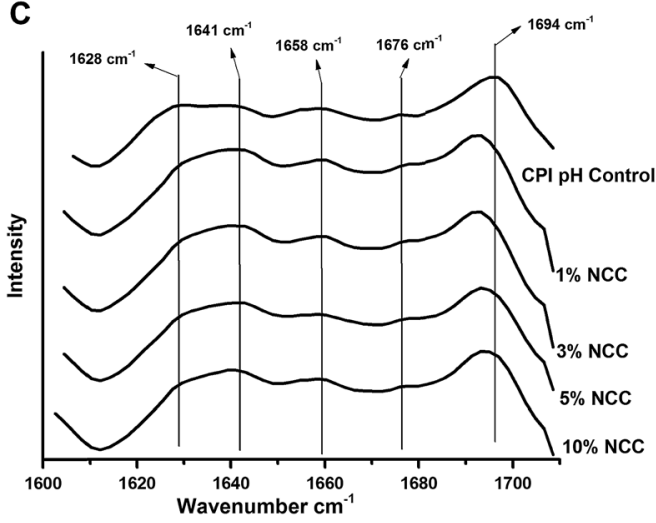

B
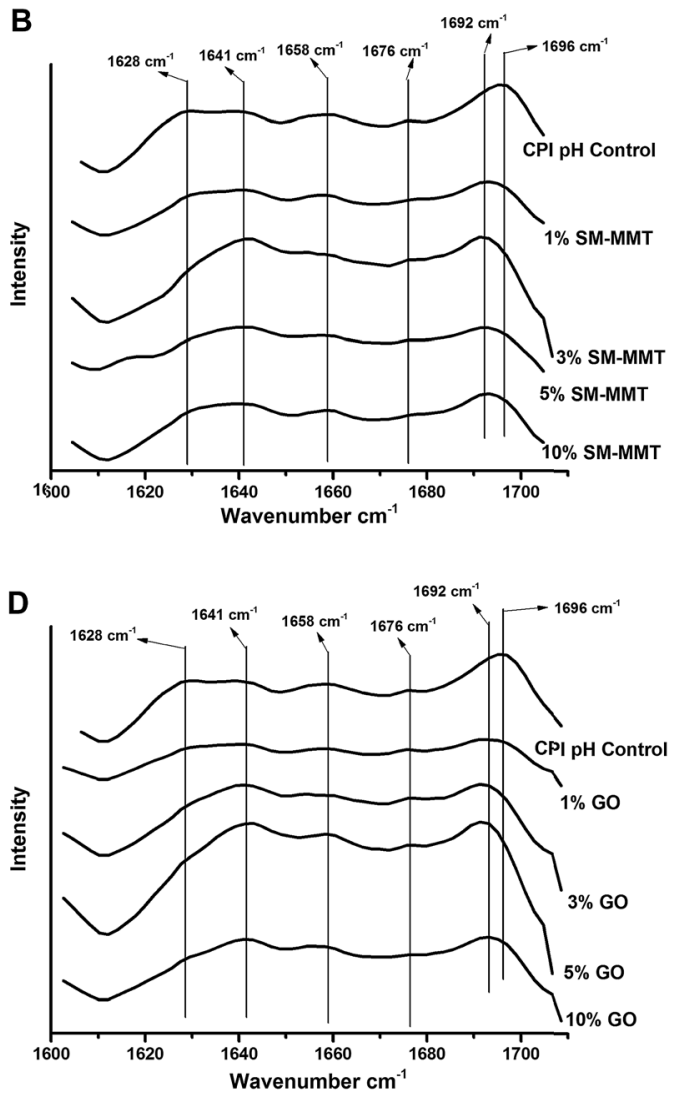

Fig. 6 Second derivative spectra of amide I peak in FTIR spectra showing protein secondary structural changes of adhesives prepared either with canola protein (CPI pH control), or by exfoliating bentonite, SM-MMT (surface modified montmorillonite), NCC (nanocrystalline cellulose), and $\mathrm{GO}$ (graphite oxide), at different nanomaterial addition levels ( $1 \%, 3 \%, 5 \%$, and $10 \% \mathrm{w} / \mathrm{w}$ nanomaterial/canola protein).

spectra after peak fitting until concentrations up to $3 \%$ or above. At increasing GO concentrations, increase in unordered structure $\left(1641 \mathrm{~cm}^{-1}\right)$ was more obvious compared to other nanomaterials, mainly at the expense of the relative proportions of $\alpha$-helix and $\beta$ sheet structure. Nanomaterial induced protein secondary structural changes were observed in previous studies as well ${ }^{44,47,48}$ where they reported decreased $\alpha$-helix and $\beta$ sheet structures ${ }^{48}$ but increased $\beta$ turns and unordered structures. ${ }^{44,48}$ These changes were attributed to the protein nanomaterial interactions such as nanomaterial induced the protein-protein interactions and exposed hydrophobic functional groups as a result of protein nanomaterial interactions, which was packed in core of protein structure. ${ }^{44}$

Results obtained from FTIR analysis of modified adhesives support the trends observed in the adhesion strength of nanomaterial incorporated canola protein adhesives. At lower nanomaterial concentration, changes in secondary structure would expose more hydrophobic functional groups and enhance interactions with the wood surface thereby increasing adhesion strength and, specifically water resistance. Increasing nanomaterial concentrations, however, would lead to drastic change of secondary structure and promote strong nanomaterial-protein interactions, thereby reducing the potential functional groups available to react with wood surface, ${ }^{20}$ which ultimately reduce adhesion strength and water resistance.
Therefore choosing an appropriate level of nanomaterial addition into canola protein matrix is important in improving adhesion strength and water resistance of canola protein adhesives.

\section{Effect of nanomaterial on thermal properties of adhesives}

Effects of nanomaterial additions at different concentrations on the thermal stability and enthalpy required for adhesive denaturation were shown in Table 1. Denaturation temperature $\left(T_{\mathrm{d}}\right)$ of a protein is an indication of thermal stability of protein. ${ }^{49}$ Extracted canola protein used for this study exhibits an onset temperature of $72.20 \pm 0.16^{\circ} \mathrm{C}$ and $T_{\mathrm{d}}$ value of $90.91 \pm 2.09^{\circ} \mathrm{C}$, which was comparable to previously reported onset temperature of $77.9{ }^{\circ} \mathrm{C}$ and denaturation temperature of $83.9{ }^{\circ} \mathrm{C}$, by Wu and Muir (2008). The slight variations of denaturation temperatures are attributed to the method of protein extraction and compositional changes of extracted protein, which has an effect on thermal stability of the protein..$^{49}$ Thermal stability is one of the properties required in developing wood adhesives where hot pressing is required in adhesive curing. In general, adding nanomaterials increased the $T_{\mathrm{d}}$ of CPI adhesives compared to the controls which could be due to strong protein-nanomaterial and protein-protein interactions. Linse et al. (2007) attributed increased thermal stability and denaturation temperatures of 
Table 1 Changes in thermal transitions of canola protein based adhesives after exfoliating bentonite, surface modified montmorillonite (SM-MMT), nanocrystalline cellulose (NCC) and graphite oxide (GO) at different nanomaterial concentrations $(1 \%, 3 \%, 5 \%$, and $10 \% \mathrm{w} /$ w nanomaterial/canola protein)

\begin{tabular}{lcrl}
\hline Sample & & & \\
\hline CPI - control & $72.20 \pm 0.16$ & $90.91 \pm 2.09$ & $1.44 \pm 0.03$ \\
CPI pH control & $88.55 \pm 4.82$ & $103.16 \pm 4.74$ & $2.53 \pm 0.02$ \\
1\% bentonite & $86.25 \pm 2.62$ & $103.79 \pm 2.28$ & $2.69 \pm 0.12$ \\
3\% bentonite & $91.75 \pm 0.69$ & $107.42 \pm 0.18$ & $2.60 \pm 0.07$ \\
5\% bentonite & $90.32 \pm 1.75$ & $105.58 \pm 2.51$ & $2.20 \pm 0.01$ \\
10\% bentonite & $87.69 \pm 1.53$ & $103.35 \pm 2.14$ & $2.14 \pm 0.06$ \\
1\% SM-MMT & $85.98 \pm 2.04$ & $102.54 \pm 2.41$ & $2.32 \pm 0.02$ \\
3\% SM-MMT & $85.80 \pm 1.32$ & $100.53 \pm 1.61$ & $1.92 \pm 0.03$ \\
5\% SM-MMT & $78.22 \pm 3.48$ & $93.02 \pm 4.82$ & $2.12 \pm 0.15$ \\
10\% SM-MMT & $84.34 \pm 5.18$ & $98.86 \pm 3.44$ & $1.84 \pm 0.04$ \\
1\% NCC & $91.84 \pm 1.73$ & $105.15 \pm 2.14$ & $2.43 \pm 0.04$ \\
3\% NCC & $85.40 \pm 2.40$ & $100.63 \pm 2.82$ & $2.12 \pm 0.03$ \\
5\% NCC & $87.82 \pm 1.28$ & $101.69 \pm 1.40$ & $1.55 \pm 0.06$ \\
10\% NCC & $84.34 \pm 5.18$ & $104.18 \pm 0.08$ & $1.56 \pm 0.05$ \\
1\% GO & $79.17 \pm 0.83$ & $96.02 \pm 0.88$ & $2.88 \pm 0.09$ \\
3\% GO & $80.66 \pm 0.47$ & $97.62 \pm 1.32$ & $2.52 \pm 0.01$ \\
5\% GO & $82.39 \pm 0.18$ & $98.20 \pm 1.64$ & $2.11 \pm 0.06$ \\
10\% GO & $80.50 \pm 1.03$ & $95.55 \pm 2.94$ & $1.48 \pm 0.02$
\end{tabular}

graphite oxide nano sheet incorporated soybean peroxidase to protein secondary structural changes. ${ }^{47}$ However, further increasing nanomaterial concentrations resulted in decreasing $T_{\mathrm{d}}$ values of CPI adhesives. This can be a result of drastic changes in protein secondary structures as evidenced by FTIR data, where they created higher degree of unordered structures, resulting lower temperature requirement for denaturation.

\section{Conclusions}

A solution intercalation method was developed to exfoliate nanomaterials in canola protein matrix as evidenced by TEM and XRD analysis. Our study showed that nanomaterials at lower addition levels (at $1 \% \mathrm{w} / \mathrm{w}$ addition) could significantly improve the adhesion strength and water resistance of canola protein adhesives. However, decrease in adhesion strength at increasing nanomaterial addition levels were observed with the exception of NCC and GO, where adhesion was improved even at $3 \%$ and $5 \% \mathrm{w} / \mathrm{w}$ levels, respectively. Our study further supported the significance of uniform dispersion and exfoliation of nanomaterial in the protein matrix. Adding nanomaterials exposed more hydrophobic and other functional groups to react with wood surface, which would increase water resistance and adhesion strength. The improvement could also be attributed to the nanomaterial-induced cohesion. In addition, the properly exfoliated nanomaterials could act as physical barriers for water penetration, contributing to improved water resistance. Among four nanomaterials tested in this study, GO and NCC proved to be superior in terms of increasing functionality of canola protein adhesives compared to bentonite and SM-MMT. Results of this study provided evidence on the potential use of nanomaterial to improve the adhesive properties of biobased wood adhesives, which may replace traditional synthetic adhesives as green alternative adhesive materials.

\section{Conflict of interest}

The authors declare no financial competing interest.

\section{Abbreviations}

$\begin{array}{ll}\text { Bento } & \text { Bentonite } \\ \text { SM-MMT } & \text { Surface modified montmorillonite } \\ \text { NCC } & \text { Nanocrystalline cellulose } \\ \text { GO } & \text { Graphite oxide } \\ \text { PVA } & \text { Polyvinyl acetate } \\ \text { XRD } & \text { X-ray diffraction } \\ \text { DSC } & \text { Differential scanning calorimetry } \\ \text { TEM } & \text { Transmission electron microscopy } \\ & \\ & \\ \text { ACknowledgements }\end{array}$

Authors would like to acknowledge Ms Jane Batcheller, Faculty Service Officer in Department of Human Ecology, University of Alberta for allowing access to Instron tensile testing machine. Authors would like to acknowledge the Alberta Innovates Biosolutions and Alberta Livestock \& Meat Agency for supporting this research. In addition, author would like to acknowledge the funding support received from Alberta Innovates Technology Futures Graduate Student Scholarship for PhD studies.

\section{References}

1 A. Pizzi, J. Adhes. Sci. Technol., 2006, 20, 829-846.

2 A. Pizzi, Rev. Adhes. Adhes., 2013, 1, 88-113.

3 X. Li, J. Luo, Q. Gao and J. Li, RSC Adv., 2016, 6, 45158-45165.

4 J. Li, X. Li, J. Li and Q. Gao, RSC Adv., 2015, 5, 80136-80141.

5 N. Bandara, L. Chen and J. Wu, Int. J. Adhes. Adhes., 2013, 44, 122-129.

6 A. Kaboorani, B. Riedl, P. Blanchet, M. Fellin, O. Hosseinaei and S. Wang, Eur. Polym. J., 2012, 48, 1829-1837.

7 C. Wang, J. Wu and G. M. Bernard, Ind. Crops Prod., 2014, 57, 124-131.

8 J. Luo, J. Luo, C. Yuan, W. Zhang, J. Li, Q. Gao and H. Chen, RSC Adv., 2015, 5, 100849-100855.

9 S. Khosravi, F. Khabbaz, P. Nordqvist and M. Johansson, Macromol. Mater. Eng., 2014, 299, 116-124.

10 Z. He, D. C. Chapital, H. N. Cheng and M. K. Dowd, Int. J. Adhes. Adhes., 2014, 50, 102-106.

11 N. Bandara, L. Chen and J. Wu, Cereal Chem., 2011, 88, 553-559.

12 W. A. R. Manamperi, S. K. C. Chang, C. A. Ulven and S. W. Pryor, J. Am. Oil Chem. Soc., 2010, 87, 909-915.

13 N. Li, G. Qi, X. S. Sun, M. J. Stamm and D. Wang, J. Am. Oil Chem. Soc., 2011, 89, 897-908.

14 M. Aider and C. Barbana, Trends Food Sci. Technol., 2011, 22, 21-39. 
15 N. Li, G. Qi, X. S. Sun and D. Wang, J. Polym. Environ., 2012, 20, 905-915.

$16 \mathrm{~K}$. Hale, The potential of canola protein for bio-based wood adhesives, Kansas State University, 2013.

17 C. Santulli, in Nanoclay reinforced polymer composites, ed. M. Jawaid, A. K. Qaiss and R. Bouhfid, Springer, Singapore, 2016, pp. 81-101.

18 A. Kaboorani and B. Riedl, Composites, Part A, 2011, 42, 1031-1039.

19 A. Kaboorani and B. Riedl, J. Ind. Eng. Chem., 2012, 18, 10761081.

20 Y. Zhang, W. Zhu, Y. Lu, Z. Gao and J. Gu, Ind. Crops Prod., 2014, 57, 35-42.

21 G. Qi, N. Li, D. Wang and X. S. Sun, J. Am. Oil Chem. Soc., 2016, 93, 1509-1517.

22 M. Arshad, M. Kaur and A. Ullah, ACS Sustainable Chem. Eng., 2016, 4, 1785-1793.

23 S. Stankovich, D. A. Dikin, G. H. B. Dommett, K. M. Kohlhaas, E. J. Zimney, E. A. Stach, R. D. Piner, S. T. Nguyen and R. S. Ruoff, Nature, 2006, 442, 282-286.

24 M. M. Reddy, S. Vivekanandhan, M. Misra, S. K. Bhatia and A. K. Mohanty, Prog. Polym. Sci., 2013, 38, 1653-1689.

25 A. Sapalidis, F. Katsaros and N. Kanellopoulos, Nanocompos. Polym. Anal. Methods, 2011, 29-50.

26 D. Marquis, C. Chivas-Joly and É. Guillaume, Properties of nanofillers in polymer, INTECH Open Access Publisher, 2011.

27 S. Stankovich, D. A. Dikin, R. D. Piner, K. A. Kohlhaas, A. Kleinhammes, Y. Jia, Y. Wu, S. T. Nguyen and R. S. Ruoff, Carbon, 2007, 45, 1558-1565.

28 B. L. Peng, N. Dhar, H. L. Liu and K. C. Tam, Can. J. Chem. Eng., 2011, 89, 1191-1206.

29 W. S. Hummers and R. E. Offeman, J. Am. Chem. Soc., 1958, 80, 1339.

30 E. D. Cranston and D. G. Gray, Biomacromolecules, 2006, 7, 2522-2530.

31 ASTM, Annual Book of Standards, ASTM D2339-98(2011), 2011.
32 ASTM, Annual Book of Standards, ASTM D1151-00(2013), 2013.

33 W. Bragg and W. Bragg, Proc. R. Soc. London, Ser. A, 1913, 88, 428-438.

34 M. Alexandre and P. Dubois, Mater. Sci. Eng., R, 2000, 28, 163.

35 B. Han, A. Cheng, G. Ji, S. Wu and J. Shen, J. Appl. Polym. Sci., 2004, 91, 2536-2542.

36 L. Zhou, H. Chen, X. Jiang, F. Lu, Y. Zhou, W. Yin and X. Ji, J. Colloid Interface Sci., 2009, 332, 16-21.

37 X. Chen, X. Deng, W. Shen and L. Jiang, BioResources, 2012, 7, 4237-4248.

38 D. Liu, X. Chen, Y. Yue, M. Chen and Q. Wu, Carbohydr. Polym., 2011, 84, 316-322.

39 K. Krishnamoorthy, M. Veerapandian, K. Yun and S. J. Kim, Carbon, 2013, 53, 38-49.

40 H. Xu, S. Ma, W. Lv and Z. Wang, Pigm. Resin Technol., 2011, 40, 191-195.

41 D. W. Hatchett and M. Josowicz, Chem. Rev., 2008, 108, 746769.

42 A. A. Keller, H. Wang, D. Zhou, H. S. Lenihan, G. Cherr, B. J. Cardinale, R. Miller and Z. Ji, Environ. Sci. Technol., 2010, 44, 1962-1967.

43 J. Schultz and M. Nardin, Handbook of Adhesion Technology, Dekker Inc., New York Basel, 2003.

44 I. Lynch and K. A. Dawson, Nano Today, 2008, 3, 40-47.

45 A. Barth, Biochim. Biophys. Acta, 2007, 1767, 1073-1101.

46 J. Kong and S. Yu, Acta Biochim. Biophys. Sin., 2007, 39, 549559.

47 S. Linse, C. Cabaleiro-Lago, W.-F. Xue, I. Lynch, S. Lindman, E. Thulin, S. E. Radford and K. A. Dawson, Proc. Natl. Acad. Sci. U. S. A., 2007, 104, 8691-8696.

48 W. Norde and C. E. Giacomelli, J. Biotechnol., 2000, 79, 259268.

49 J. Wu and A. D. Muir, J. Food Sci., 2008, 73, C210-C216. 